\title{
Managing waste in hotel and its impact on environment
}

\author{
Garima Jain* \\ Bhikaji Cama Subharti Institute of Hotel Management \\ Swami Vivekanand Subharti University, Meerut-250005 \\ *Corresponding author: garimajainjain@ymail.com
}

\begin{abstract}
Hotel industry, in recent years, has been a major consistent force behind the tremendous growth in Indian GDP. It has also fueled the increase in number of hotels around the country. Hotels are the major consumers of resources and contribute heavily toward the waste generation, as compared to others. The study aims to know the current status of use of energy resources; the amount and type of waste generated; the waste management practices followed by hotels. Kitchen waste is defined as left-over organic matter from restaurants, hotels and households. Tons of kitchen wastes are produced daily in highly populated areas. Kitchen wastes entering the mixed-municipal waste system are difficult to process by standard means, such as incineration, due to the high moisture content. Furthermore, organic matter can be transformed into useful fertilizer and bio-fuel. New disposal methods that are both environmentally and economically efficient are being developed which rely on various forms of microbial decomposition.
\end{abstract}

Keywords: Hotel, Waste, Front Office, Food and Beverage, Housekeeping

Paper cited: Jain, G. (2016). Managing waste in hotel and its impact on environment. South Asian Journal of Food Technology and Environment, 2(1): 330-333

Received: 11/01/2016 Revised: 19/02/2016 Accepted: 07/03/2016

\section{Introduction}

Indian hospitality and tourism sector is the third largest foreign exchange earner, after gems and jewellery and readymade garments. It's contribution in Indian GDP is $6.4 \%$, with an annual increment of $7.8 \%$ per annum. Whereas, in world's GDP, it is $9.1 \%$, and rising with a rate of $4.3 \%$ per annum (World Travel and Tourism Council (WTTC), Its significance also increases in the context that this industry is the world's largest employer, generating 254,941,000 jobs which mean that nearly one out of every 12 jobs is from this sector (WTTC). This clearly indicates the economic importance of the sector, and maximum of the country's tourism potential is still untapped. As per the report of Ministry of Tourism (GOI, 2012), India received 6,290,319 international tourist. From figures it is clear that tourism industry has experienced a large growth in the recent decade. This has fueled demand for hotels; which means that the waste amount from the hotels will grow more rapidly. Due to their nature, hotels are massive consumer of resources and produce more waste. But, existing guidelines do not ask for efficient use and management of these resources and waste. However, in the long run managing use of these will not only have a major effect in increasing the profit of the hotel industry, but also will contribute to the long-term sustainability of this sector (Alamoudi, 2009). Hence it becomes necessary to focus on the hotel waste management. It must be managed from production to till disposal. This strategy should consist of engineering solution, education, and compliance by everyone who deals with the hotel waste.

\section{Recycling program}

- Conduct a waste audit to identify and quantify recyclable materials currently being thrown away.

- Select a materials disposal method before designing the recycling program.

- Involve the hotel's employees in all stages of the recycling program.

- Design a materials flow plan to identify container size and placement

- Select recycling equipment and method(s) of transporting materials. 
Eco-purchasing program

- Reduce waste by purchasing in bulk or concentrate.

- Reduce toxicity by using products with less hazardous ingredients.

- Avoid wasteful products that add to the environmental or economic costs of waste disposal.

- Repair and reuse products instead of buying new ones.

- Select products made from recycled materials.

- Purchase energy efficient equipment that causes less environmental harm

What is a "green" hotel?

A "green" hotel uses resources wisely, incorporating energy, water, recycling and waste reduction techniques into the daily hotel operations. There are a number of advantages for "green" hotels.Most actions that save resources and reduce pollution,also reduce operating costs and increase profit margins.Involvement in "green" issues can develop and strengthen guest loyalty . Hotel managers report that most guests are pleased to see the hotel recycling and are willing to participate in the hotel's program. To increase guest involvement,inform guests about the program when they check-in. Some hotels provide guests recycling information cards at the check-in desk or in the guest rooms. This awareness allows both the guest and the hotel to participate in the growing interest in ecotourism.

\section{Why take action?}

By taking a few simple steps to waste less and recycle more, and by working out the cost of food waste to the business, hotels can reap financial as well as environmental benefits.

\section{Where is waste generated?}

Hotels often say they waste very little food as the plates generally come back clean. However, food waste comes from a variety of sources;
- Spoiled or out of date food

- Peelings \& trimmings

- Inedible by-products, e.g. bones, coffee grounds, tea leaves

- Kitchen error

- Plate waste

\section{Optimizing your food recycling programme}

- Get the bins right. Incorrect types and numbers of bins can lead to the wrong waste going in the wrong bin, such as recycling going in with general waste. Adjusting the size of bins or frequency that they are collected can also save money.

- Choose the most appropriate waste management solution for your needs. When entering into a contract for food waste recycling, or other waste collections, make sure that the service meets your requirements and won't incur additional costs.

- Ask the waste management contractor for your data. Having data on how much waste is going to landfill, being recycled or going to $\mathrm{AD}$ will help to understand current levels of recycling. This information can then be used to identify further opportunities.

- Get staff on your side. Engage staff to recycle more by helping them to understand which waste goes in which bin. It is key for staff to 'buy in' to initiatives so that they see the benefits. This will encourage participation and help increase recycling rate.

- Work together. Consider working with neighboring businesses to procure food waste and recycling collections, where appropriate. There may be efficiencies/economies of scale to be made by working together. 


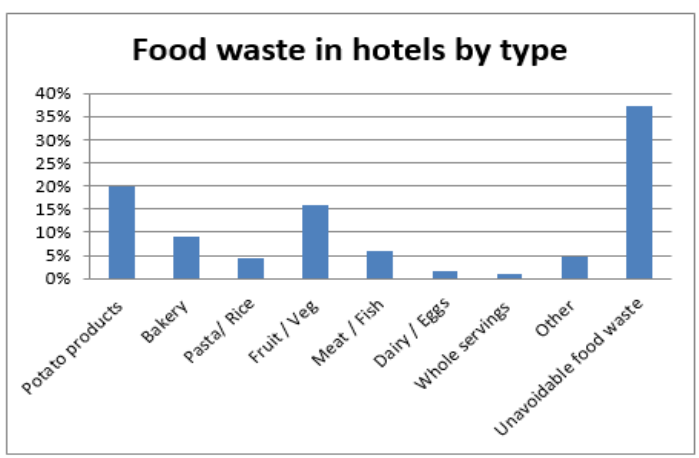

Fig. 1: Food Wastes in Hotel

\section{Guidelines for housekeeping department}

This department is responsible for maintaining hygiene and cleanliness in the hotel. Some of the practices, they can adopt, are:

\section{Avoiding}

- As the hotels (small hotels) are of not very luxurious in nature, we can afford to position newspapers in centrally located news stands at places such as lobby or restaurant, so that paper waste can be minimized.

- Don't use plastic bags.

- Eliminate the use of plastic liners in garbage bins.

- Go for natural fiber mattress. And if not possible, ask mattress manufactures to repair damaged mattresses rather than disposing these as they are made up of synthetic material. Mattress manufacturers will rebuild to the hotel's specifications.

- Avoid purchasing diluted cleaning and laundry solutions, by concentrated products.

- Don't buy vacuum cleaners with disposables bags.

- Purchase cloth material of a high thread count for longer life.

- Instead of disposables, supply reusable glasses and cups for guests.

- Always use pump-style sprays in-place of aerosol cans.

\section{Reducing}

- Replace supplies in guest room when they are almost empty or ask your guests if they want fresh supplies or not.

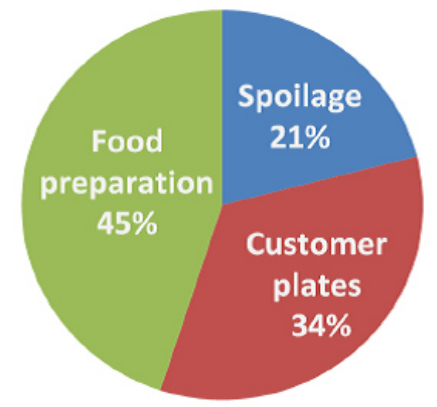

Fig 2: Show the waste food material

- Supply guest amenities which are not used very often on request.

- Reduce concentration of cleaning solutions to prescribed level.

- Use environment friendly washing solutions

- Decrease the use of pesticides in the hotel.

\section{Reusing}

- Use refillable soap, shampoo and other toiletry dispensers in guest rooms. By this way we can eradicate waste soap pieces, wrappers and plastic bottles.

- Opt for refinishing and reupholstering of damaged and outdated furniture, rather than buying new.

\section{Recycling}

- If possible, use damaged bath towels as hand or face towels or cleaning cloths.

- Use recycled paper fibers made tissue and paper products.

- Recycled plastics made Housekeeping carts, waste containers, caddies, and mop buckets should be used.

- If possible recycled material furniture should be used.

\section{Guidelines for food and beverage department}

Food and Beverage department provides food and beverage items to guests. Hence it is also one of the main waste producing sections of hotels

\section{Avoiding}

- Don't buy disposables.

- Avoid items such as water, sauces and gravies in small packing. Ask your 
suppliers to provide these in returnable and refillable packaging.

- Use refillable dispensers instead of single or small packets.

- Always use reusable presentation materialas a replacement for food presentations.

- Food and Beverage linen must have a Reducing high thread count for longer life.

- Reduce use of small plastic bottles for water; rather install a centralizeed use of water purifier.

- Decrease energy consumption of cooking equipment by installing efficient equipment.

- Install a washing system that uses minimum water and energy.

- Maintain food and beverage area temperature between $25-270 \mathrm{C}$

\section{Reusing}

- Use reusable coasters in place of paper coasters.

- Reuse the leftovers to make suitable Recycling dishes or donate them to needy people.

- Recycle the food waste and supply other type of waste for suitable recycling.

- Use damaged linen for wiping crockery and cutlery

\section{Guidelines for other areas}

Other offices such as front office, accounts and finance, human resource etc. also contribute significantly to the solid waste material.

\section{Avoiding}

- Don't buy unnecessary packaged products.

- Avoid using disposable batteries, use rechargeable ones.

- Never use waste bin bags in bins which are meant for collecting paper waste.

- As far as possible avoid use of paper for Reducing notices or other purposes, use e-mails.

- Reduce font size by one and spacing between lines, this can save a lot.
- Keep the office AC temperature between 25-270C

- Install CFLs or LEDs.

- Use maximum sunlight in day.

Reusing

- Use paper from both sides, for printing.

- Ask for refillable cartridges.

Recycling

- Donate unusable printer cartridges, paper, plastic and other waste material for recycling.

\section{Conclusion}

In the changing scenario of increase in environmental issues, government rules, ecological awareness amongst consumers and competitive market situation has forced other industries to focus on better waste management. Same is in the pipeline for hotel industry. For this, the researchers have tried to establish the current status of energy resources used; the amount and type of waste generated; the waste management practices followed by small hotels. Though, almost all of the hoteliers have agreed that they should use resources in a better way to minimize waste. But the only factor that limits them is availability of adequate finance, as these hotels are mostly run by families or small scale businessmen. They not only lack in funds but also in expertise to manage waste. For this purpose, Govt should provide some subside or incentives or tax rebates and necessary expertise for hotels who are willing to adopt environment friendly waste management practices. This study rings warning bells not only to the policymakers but also for the hoteliers to warn them about the issue; so that they can draw strategies, together, before it is too late. Though, it brings dark area under light but still the results are confined only to the state; so generalization of findings is very difficult. But it opens a novel avenue for future research.

\section{References}

1. Alamoudi, R. H. (2009). Resource Use, Waste, and Total Productivity Management in Saudi Arabia Hotel Industry. International Journal of Basic and Applied Sciences, 9(10): 43-53. 